\title{
Wideband Circularly Polarized SIW Antenna Array That Uses Sequential Rotation Feeding
}

\author{
Fang-Fang Fan, Ze-Hong Yan, and Wei Wang \\ Science and Technology on Antenna and Microwave Laboratory, Xidian University, Xi'an, Shaanxi 710071, China \\ Correspondence should be addressed to Fang-Fang Fan; fffan@mail.xidian.edu.cn
}

Received 19 November 2013; Revised 12 March 2014; Accepted 24 March 2014; Published 10 April 2014

Academic Editor: Jong-Won Yu

Copyright (C) 2014 Fang-Fang Fan et al. This is an open access article distributed under the Creative Commons Attribution License, which permits unrestricted use, distribution, and reproduction in any medium, provided the original work is properly cited.

\begin{abstract}
A wideband right-handed circularly polarized (CP) substrate integrated waveguide- (SIW-) based diamond ring-slot antenna array at the X-band is presented in this study. The array consists of four elements that exhibit wideband impedance matching characteristics and good radiation performance. The array also employs a sequential rotation feeding method to achieve the wideband axial ratio (AR) bandwidth. The feeding network is based on the SIW power divider with a delay line related to sequential rotation feeding. To validate our design, an antenna array is fabricated and measured. The measured impedance and AR bandwidths are 19.2\% (VSWR $<2$ ) and 14.1\% (AR < $3 \mathrm{~dB})$, respectively. Moreover, the antenna has a stable CP peak gain of more than $12 \mathrm{dBic}$ from $10.1 \mathrm{GHz}$ to $10.7 \mathrm{GHz}$.
\end{abstract}

\section{Introduction}

Circularly polarized (CP) antennas can solve problems in wireless channels, such as polarization mismatch generated by the Faraday effect and interference generated by the multipath effect. CP antennas are extensively used in space applications such as satellite communication and radar systems. Among many kinds of antennas, printed-slot $\mathrm{CP}$ antennas have a large bandwidth, a low profile, excellent CP characteristic, and bidirectional radiation. Thus, a reflector board at a distance of a quarter of a wavelength at the center frequency from the bottom of the antenna must be used to obtain a unidirectional $\mathrm{CP}$ radiation wave, which will add to the height of the entire antenna. The substrate integrated waveguide (SIW) transmission structure [1], using via arrays to replace the side walls and as metallic rectangular waveguides with the printed circuit board (PCB) process, exhibits the advantage of having high power transmission and low radiation loss characteristic. A SIW-based slot antenna can improve the radiation efficiency because of its low loss characteristic. Such antenna can also achieve a unidirectional radiation with its SIW structure.

To date, numerous SIW-based slot antennas have been reported in the literature [2-11]. A 16-element top-wall SIW slot antenna [2] proposed two-compounded slot pairs to obtain a $\mathrm{CP}$ wave centered at $16 \mathrm{GHz}$; however, the usable bandwidth is just $2.3 \%$. In [3], the authors proposed an $\mathrm{X}$-band cavity-backed crossed-slot antenna fed by a single grounded coplanar waveguide. Both of these antennas exhibited the same problems, that is, a narrow impedance bandwidth less than 3\% and a narrow axial ratio bandwidth (ARBW) of approximately $1 \%$ for AR less than $3 \mathrm{~dB}$. A bandwidth-enhanced, cavity-backed slot antenna that uses a dual-mode, SIW-backed cavity was proposed in [4], in which impedance bandwidth was improved from $3.8 \%$ to $6.3 \%$. However, the aforementioned antennas typically suffer from a low gain less than $6 \mathrm{dBic}$. In [5-7], single-layered, ring-slot CP SIW antennas were designed. The ARBW and impedance bandwidth of these antenna were improved, but the ARBW remained unsatisfactory in some applications.

In this study, a $2 \times 2$ sequential rotation feeding array like microstrip structure [12-19] is proposed to increase the AR bandwidth and antenna gain. The element for the array adopts a diamond ring-slot antenna with an ARBW of $3.4 \%(\mathrm{AR}<3 \mathrm{~dB})$, which is larger than those in the aforementioned antennas [2-7]. Finally, the AR bandwidth for the array is increased to $14.1 \%$, and the measured antenna gain is $13.48 \mathrm{dBic}$ at $10.3 \mathrm{GHz}$ in the boresight direction. 


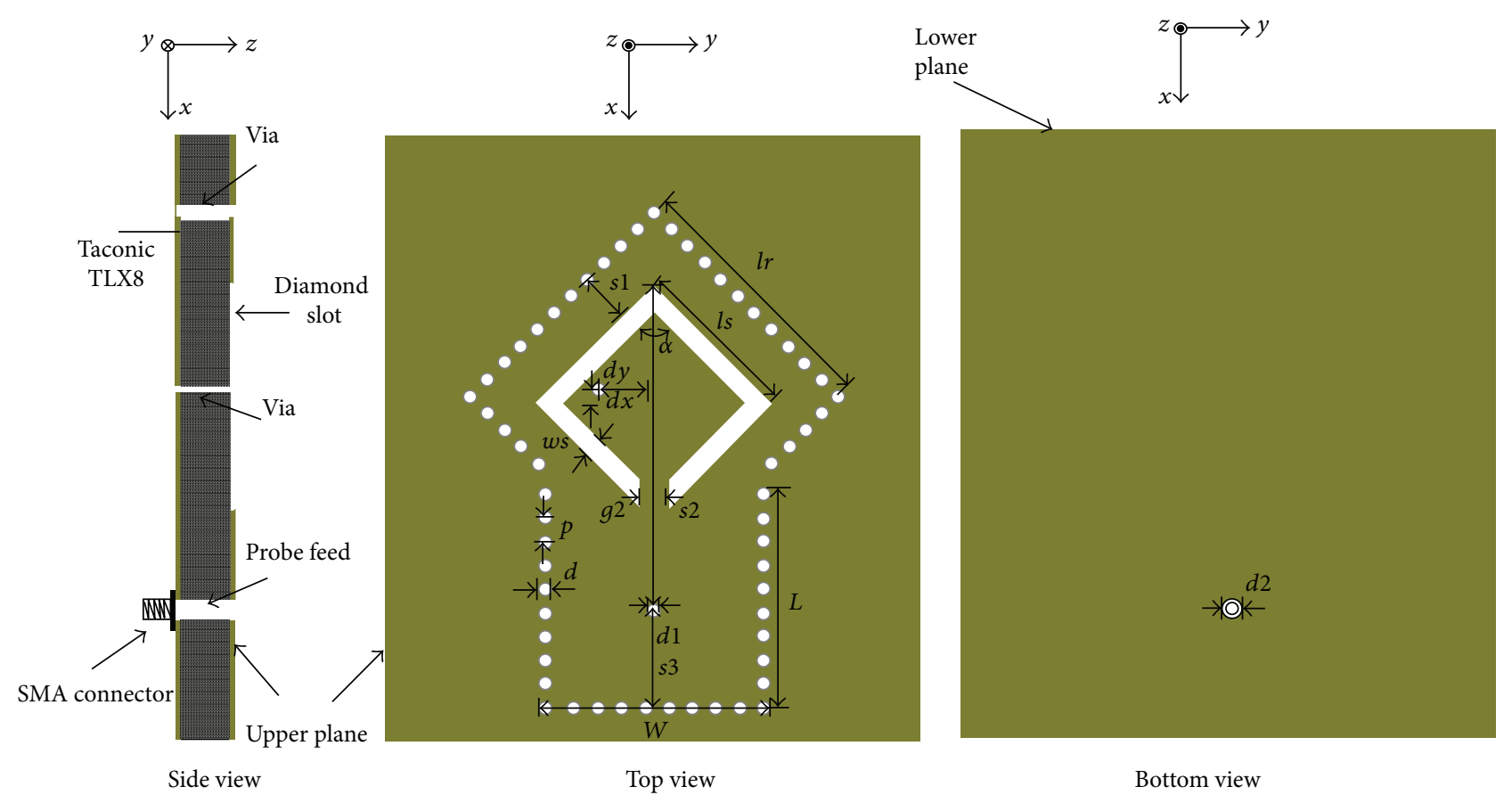

FIgURE 1: Configuration of the SIW-based element.

\section{Antenna Design and Discussion}

2.1. Element Design. A simple SIW-based antenna at the Xband is used as the element in the $2 \times 2$ antenna array. The geometric configuration of the antenna is shown in Figure 1. The antenna is composed of three parts: a SIWbased rectangular waveguide, a diamond ring-slot with a shorted strip, and a shorting via and coax feeding probe. The overall size of the SIW antenna is $45 \mathrm{~mm} \times 40 \mathrm{~mm} \times$ $1.52 \mathrm{~mm}$. Its design parameters are given in Figure 1. $p$ and $d$ are the distance between the two vias and their diameters, respectively, in the SIW structure. In order to make SIW equivalent to the conventional waveguide, the ratio of $d$ and $p$ should be more than 0.5 , and the ratio of $d$ and free space wavelength at the center frequency should be less than 0.01 . $W$ and $L$ are the width and length of the SIW structure, respectively, except for the diamond-shaped SIW structure. The width $W$ has been decided as $16.2 \mathrm{~mm}$ by setting the SIW operated at the fundamental mode ( $\mathrm{TE}_{10}$-mode). The side length of the diamond-shaped SIW structure is denoted by $l r$, which mainly determines the resonating frequency of the SIW antenna. And the inner angle of the diamond is $90^{\circ}$. The diamond ring-slot is located on the top wall of the SIW with a width of $w s$, which is in the center of the SIW in the $y$ direction. $s 1$ is the distance between the diamond ring-slot and diamond-shaped vias. The distance between the top diamond slot and the feeding probe is denoted by $s 2$. The inner dimension of the diamond ring-slot is $l s . g 2$ is the length of the shorted strips. The distance between the feeding probe and the short-ended SIW is denoted by $s 3$, which is in the center of the SIW in the $y$ direction. The location of the shorting via is denoted by $d x$ and $d y$
TABLE 1: The values of the simulated design parameters.

\begin{tabular}{lccc}
\hline Parameters & Values $(\mathrm{mm})$ & Parameters & Values $(\mathrm{mm})$ \\
\hline$W$ & 16.2 & $d x$ & 1.0 \\
$L$ & 15.8 & $d y$ & 4.4 \\
$l s$ & 12.5 & $g 2$ & 2.0 \\
$w s$ & 1.5 & $s 1$ & 3.8 \\
$p$ & 1.8 & $s 2$ & 23.8 \\
$d$ & 1.0 & $s 3$ & 7.6 \\
$d 1$ & 1.4 & $l r$ & 19.3 \\
\hline
\end{tabular}

with a diameter of $0.3 \mathrm{~mm}$. Figure 2(a) shows the reflection coefficient plots with different $l s$ versus frequency with other parameters unchanged. It can be seen that, with the increased $l r$, the resonating frequency moves to the lower frequency. Different $s 3, d x$, and $d y$ that affect the reflection coefficient are plotted in Figures 2(b), 2(c), and 2(d). It can be seen that parameters $s 3, d x$, and $d y$ also influence the impedance matching characteristic of antenna. Parameters $d x$ and $d y$ and the diameter of shorting via affect the AR bandwidth of antenna.

To obtain a right-handed circular polarization (RHCP) wave, two orthogonal modes have to be achieved. In the current study, the location of the shorting via and the shorted strip with width $g 2$ are important parameters to achieve the best CP characteristic. Through mass simulation and optimization, the final optimized parameter values for best impedance matching and AR characteristic are shown in Table 1. The proposed antenna is designed with the aid of HFSS (ANSYS Inc., USA) based on the finite element method 


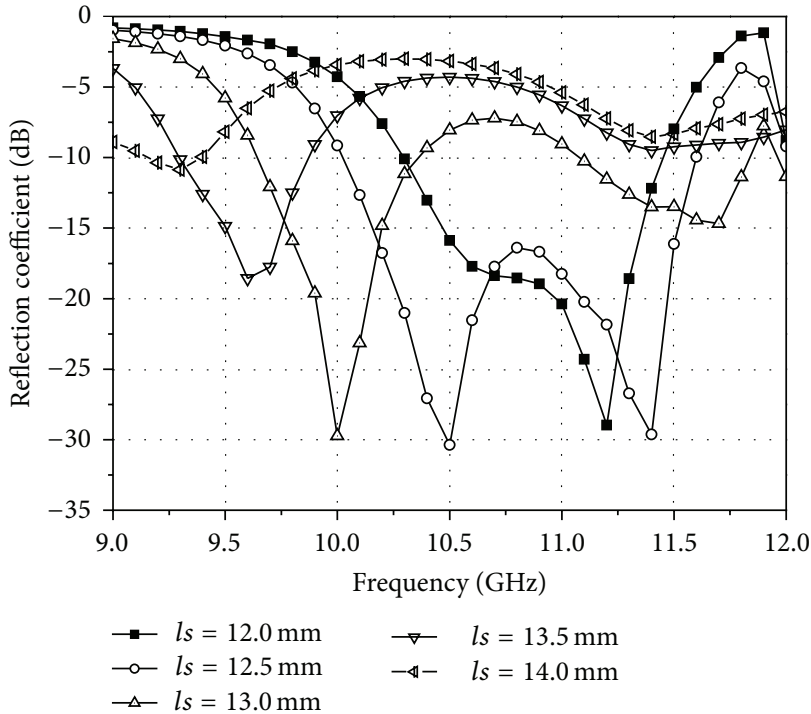

(a)

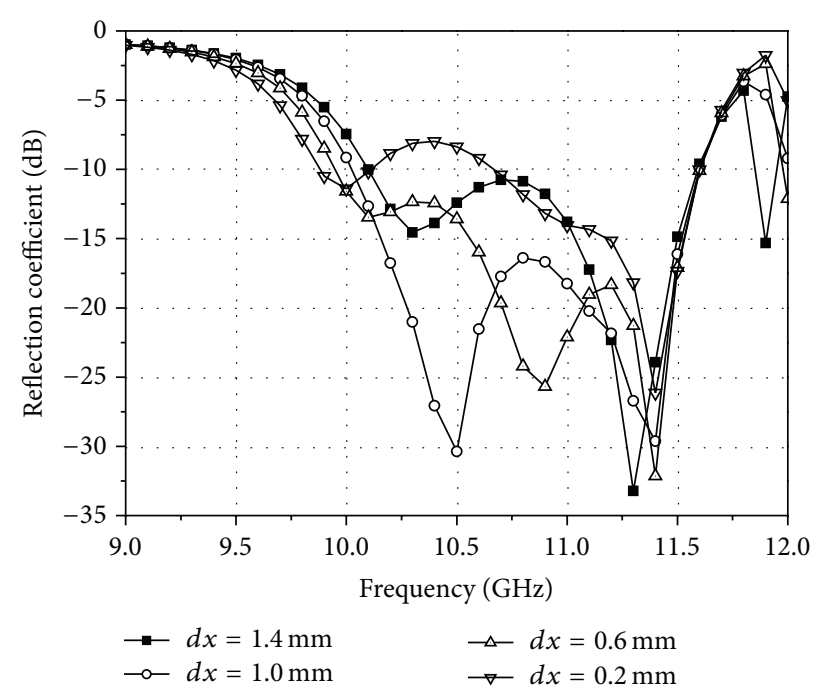

(c)

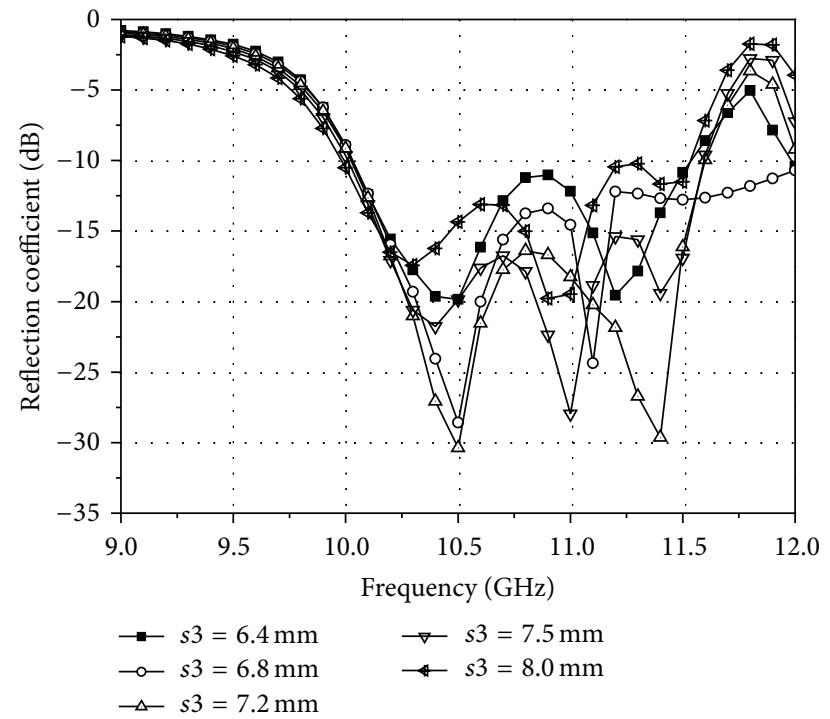

(b)

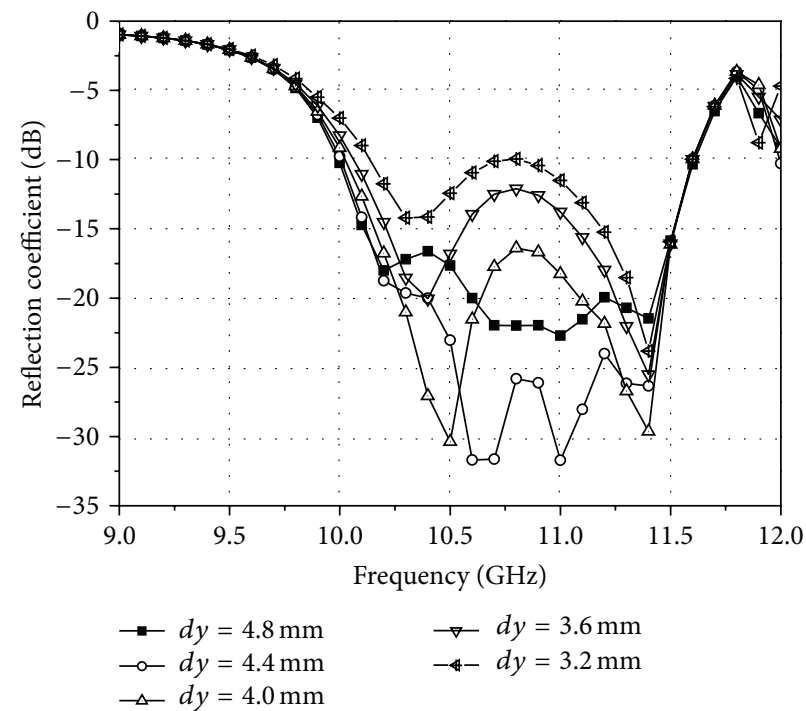

(d)

FIGURE 2: Impedance matching characteristics according to the variation of (a) $l s$, (b) $s 3$, (c) $d x$, and (d) $d y$.

(FED). A dielectric substrate Taconic TLX-8 with a relative permittivity of 2.55 , a loss tangent of 0.0019 , and a height of $1.52 \mathrm{~mm}$ is used for the antenna. After fabricating through the PCB process, the antenna is measured with the aid of the vector network analyzer E8363B. The measured and simulated return losses are shown in Figure 3 . The bandwidth with a return loss (RL) of more than $10 \mathrm{~dB}$ is $14.5 \%$ (from $10.03 \mathrm{GHz}$ to $11.60 \mathrm{GHz}$ ), the simulated RL bandwidth is $14.7 \%$ (from $10.0 \mathrm{GHz}$ to $11.59 \mathrm{GHz}$ ), the simulated RL bandwidth is a bit wider than the measured one, and the measured RL bandwidth resonant depth is lower than the simulated one which is maybe caused by the fabrication errors and the influence of the SMA connector which is not included in the simulation. The peak gain and the AR results are given in Figure 4 for simulated and measured comparison. The measured peak gain in the boresight direction is $8.1 \mathrm{dBic}$ at $10.4 \mathrm{GHz}$, whereas the measured ARBW below $3 \mathrm{~dB}$ is $3.4 \%$ (from $10.16 \mathrm{GHz}$ to $10.51 \mathrm{GHz}$ ). The simulated and measured peak gains and AR results are in good agreement. Figure 5 shows the simulated vector surface current distribution of the proposed antenna at $10.3 \mathrm{GHz}$. It is observed that the vector surface current distributions in $180^{\circ}$ and $270^{\circ}$ are equal in magnitude and opposite in phases $0^{\circ}$ and $90^{\circ}$. With the phase change, it can also be observed that the maximum currents located at the azimuth angle turn in the anticlockwise direction and the currents turn the $x$-axis into $y$-axis like a RHCP wave.

2.2. Array Design. To improve the narrow ARBW (3.4\%) and to enhance the antenna gain, a four-element array is 


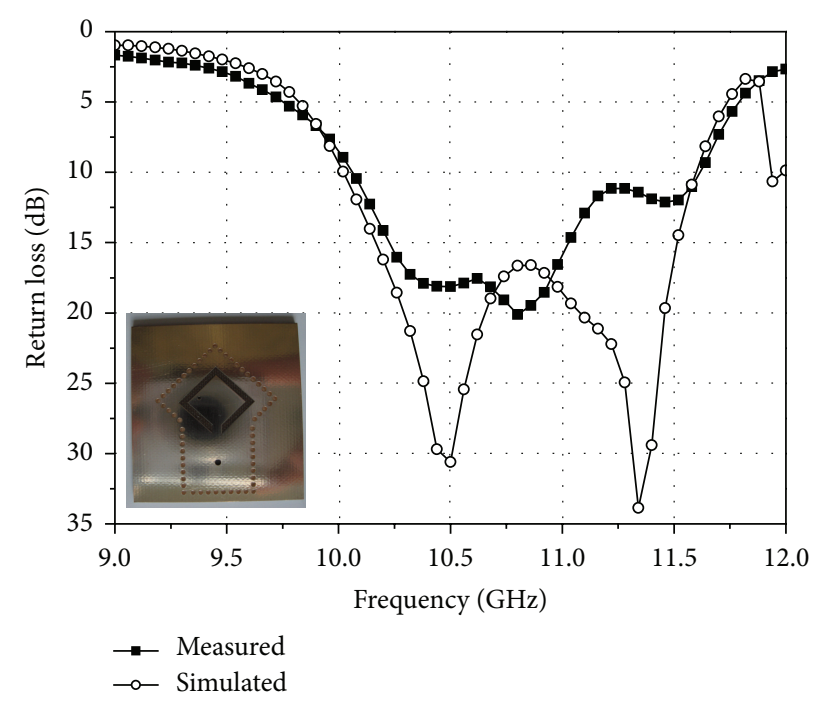

FIGURE 3: Simulated and measured return losses versus frequency.

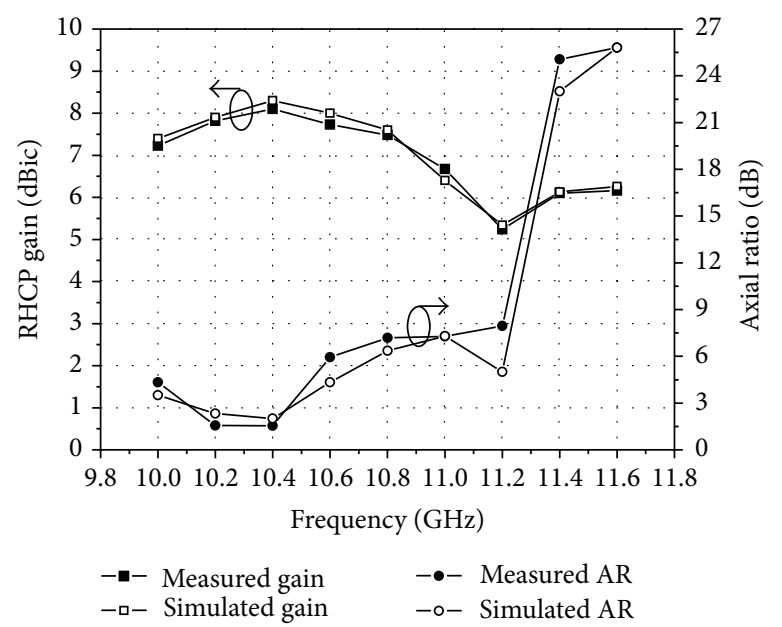

FIGURE 4: Measured peak gain and AR versus frequency.

obtained based on the aforementioned SIW-based element. The four elements are located via a sequential rotation feeding technique. In this study, the feed network for the array also adopts a SIW power divider with a radial configuration to improve radiation efficiency and to enable easy fabrication. The array employs two substrates with the same permittivity of 2.55 , loss tangent of 0.0019 , and height of $1.52 \mathrm{~mm}$. The antenna element is etched on the top substrate, and the SIW power divider is etched on the bottom substrate. The two substrates can then be glued together after fabrication. The top and bottom layers of the array are shown in Figure 6. Parameter $d i$ is the separated distance between the elements. A small $d i$ introduces mutual coupling that reduces radiation performance, whereas a big $d i$ increases antenna size. In the present study, $d i$ is optimized as $0.78 \lambda_{0}=20.01 \mathrm{~mm}$ for optimal gain and AR characteristic. Parameter $s$ is the distance from the SIW shorted end to the feed location, which is denoted by $s=7.5 \mathrm{~mm}$. $d$ is the length of the delay line with an electrical length of $90^{\circ}$ to compensate for the phase caused by sequential rotation. The value of $d$ is important for ARBW. After optimization, the final value of $d$ is $3.1 \mathrm{~mm}$. The coax feeding probe is located in the center of the SIW power divider.

\section{Experimental Results}

The two substrates for the array antenna also employ Taconic TLX- 8 with a relative permittivity of 2.55 , a loss tangent of 0.0019 , and a height of $1.52 \mathrm{~mm}$. The fabricated SIW antenna array that follows the aforementioned design parameters is shown in Figure 7. The total occupying area of the array is $W \times L=90.7 \mathrm{~mm} \times 84.5 \mathrm{~mm}$, with a height of $3.04 \mathrm{~mm}$. The four coax probes for each element on the top and bottom substrate are connected to guarantee that the energy from the input port is transmitted to the radiating layer, 

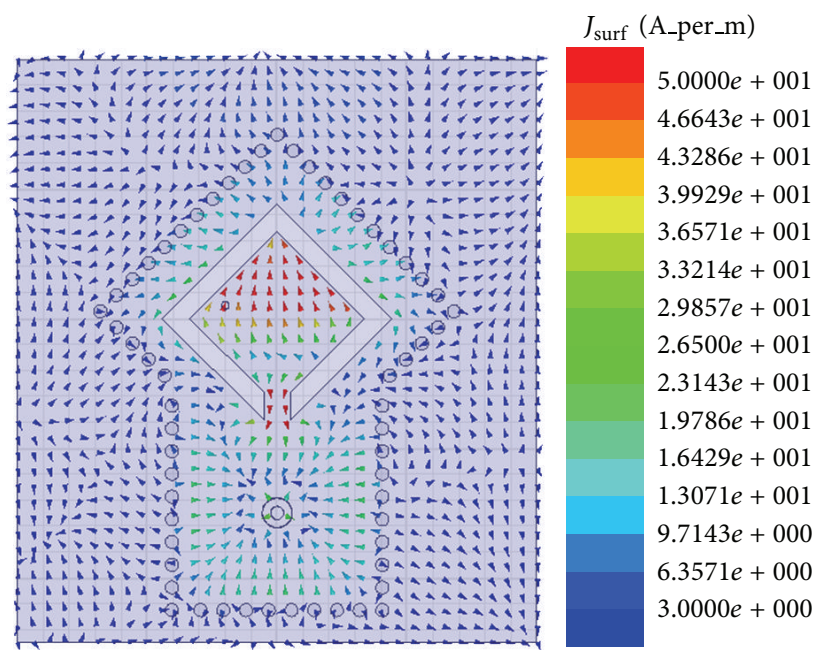

$0^{\circ}$

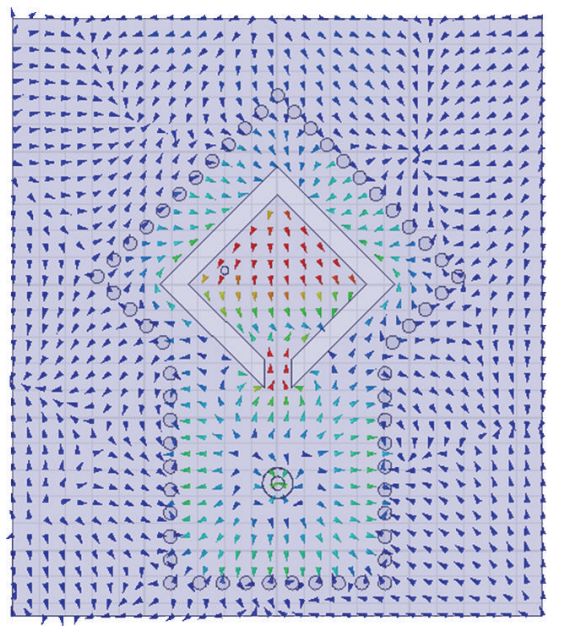

$J_{\text {surf }}$ (A_per_m)

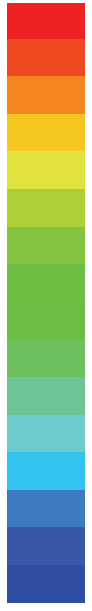

$5.0000 e+001$
$4.6643 e+001$
$4.3286 e+001$
$3.9929 e+001$
$3.6571 e+001$
$3.3214 e+001$
$2.9857 e+001$
$2.6500 e+001$
$2.3143 e+001$
$1.9786 e+001$
$1.6429 e+001$
$1.3071 e+001$
$9.7143 e+000$
$6.3571 e+000$
$3.0000 e+000$

$180^{\circ}$

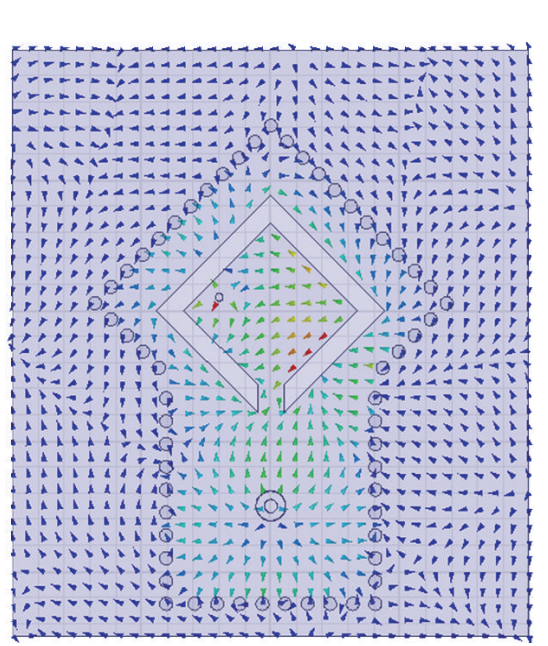

$J_{\text {surf }}($ A_per_m)

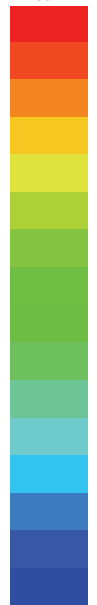

$5.0000 e+001$

$4.6643 e+001$

$4.3286 e+001$

$3.9929 e+001$

$3.6571 e+001$

$3.3214 e+001$

$2.9857 e+001$

$2.6500 e+001$

$2.3143 e+001$

$1.9786 e+001$

$1.6429 e+001$

$1.3071 e+001$

$9.7143 e+000$

$6.3571 e+000$

$3.0000 e+000$
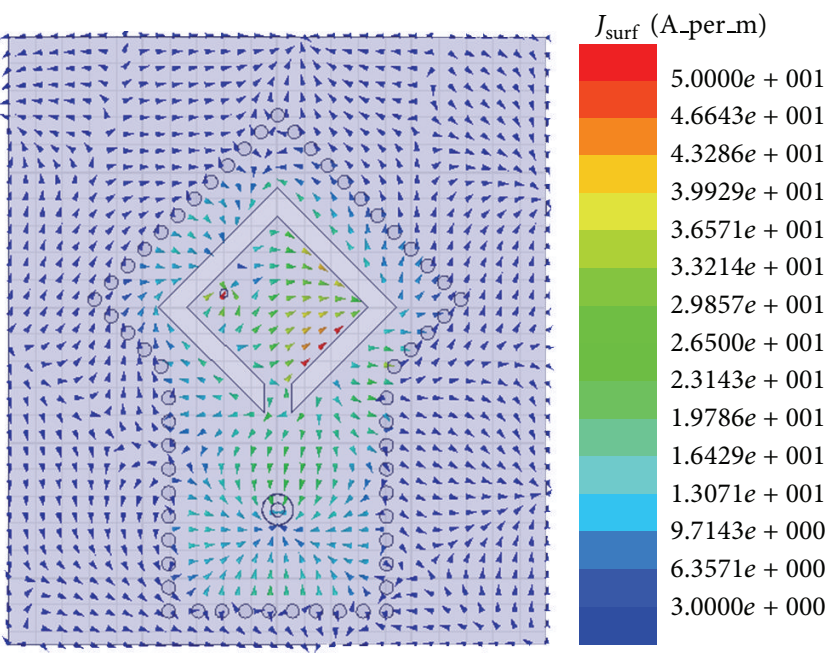

$270^{\circ}$

FIGURE 5: Distribution of the vector surface current on the diamond ring-slot of the proposed antenna at $10.3 \mathrm{GHz}$ in $0^{\circ}, 90^{\circ}, 180^{\circ}$, and $270^{\circ}$ phase.

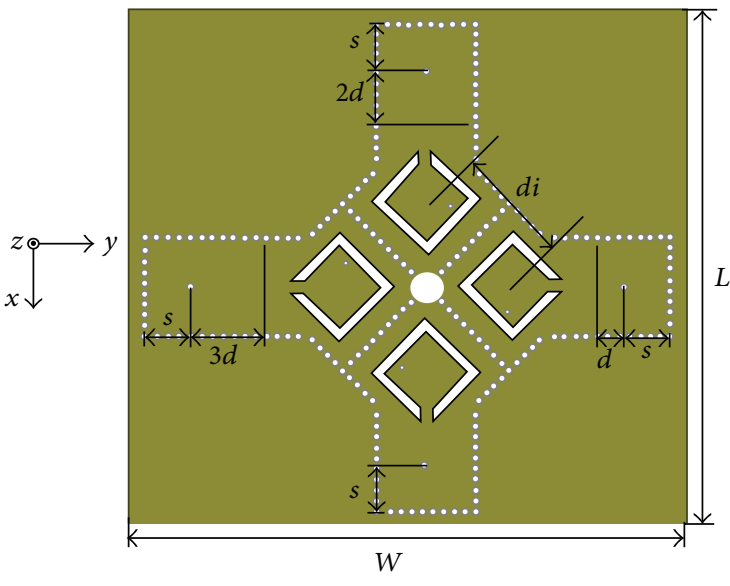

(a)

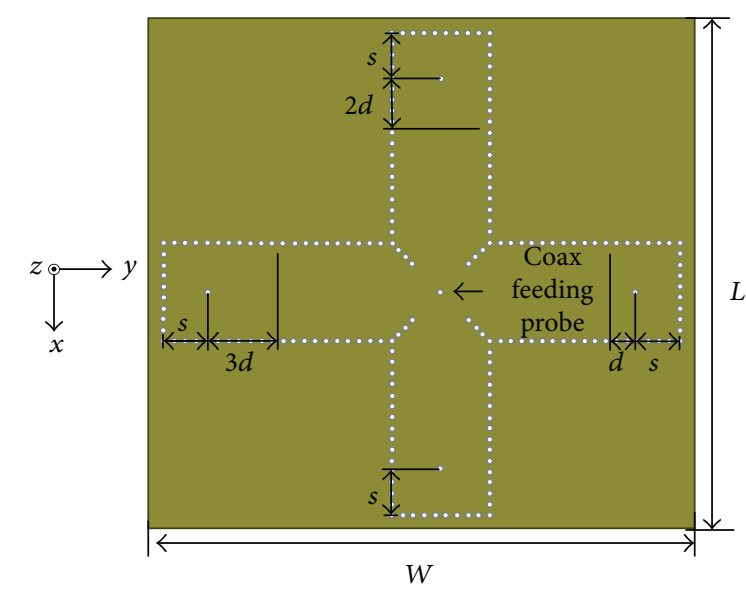

(b)

FIgURE 6: Layout of the $2 \times 2$ antenna array with (a) radiating patch on the top layer and (b) power divider on the bottom layer. 


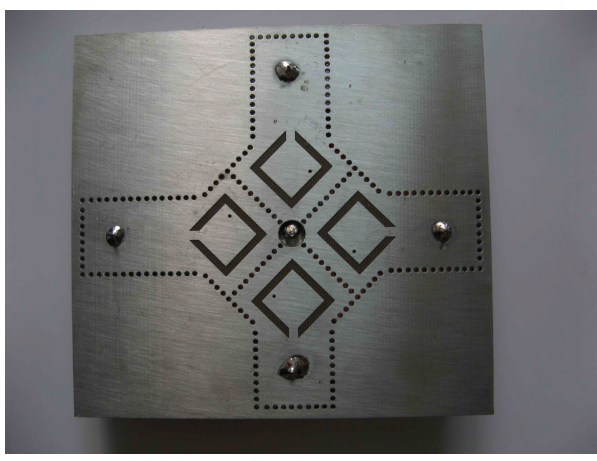

(a)

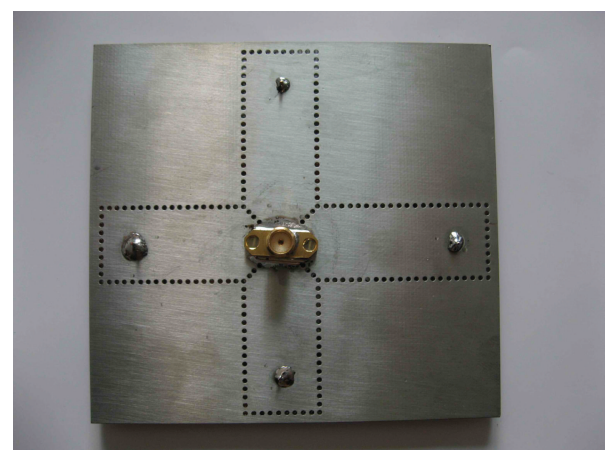

(b)

FigURE 7: Fabricated antenna array: (a) top layer and (b) bottom layer.

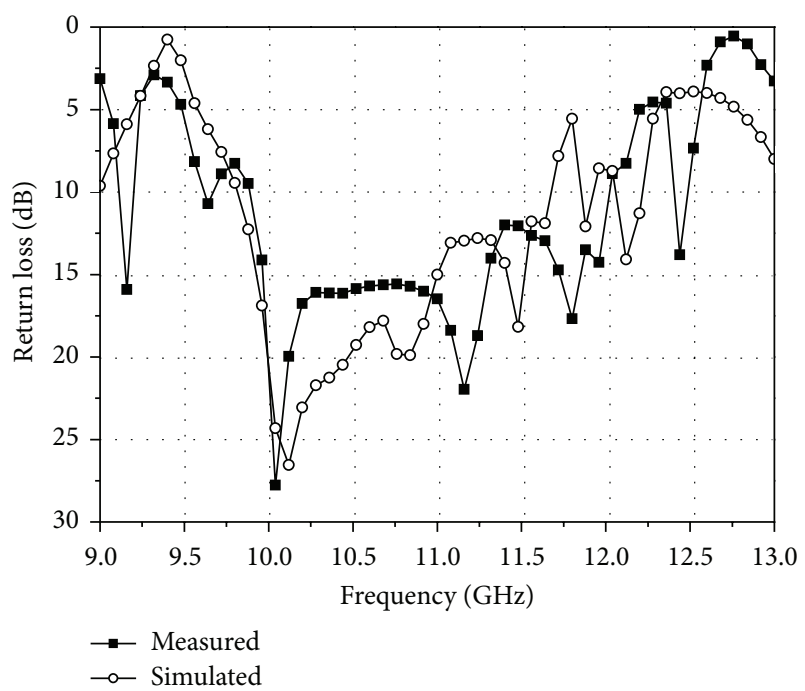

FIGURE 8: Simulated and measured return losses against frequency.

as shown in Figure 7. A hole in the center, with diameter $5.5 \mathrm{~mm}$, is cut from the top substrate to allow convenient soldering of the SMA connector. This process does not influence the impedance and radiation performance of the antenna. Return loss measurement is conducted with the aid of the vector network analyzer E8363B (Agilent Technologies, USA). The return loss bandwidth (RLBW) is $19.2 \%$ (from 9.9 GHz to $12.0 \mathrm{GHz}$ ), and the measured RLBW is larger than the simulated one, as shown in Figure 8. This difference can be attributed to tolerance error in the fabrication process.

For the radiation performance, the measured and simulated RHCP and LHCP radiation patterns in $x o z$ and yoz planes at $10.3 \mathrm{GHz}$ of the SIW antenna array are plotted in Figures 9(a) and 9(b), respectively. The proposed antenna satisfies the RHCP generation with a lower cross-polarization in the boresight direction.

The AR and peak gain results versus frequency, with simulated and measured values, are depicted in Figure 10. The measured ARBW below $3 \mathrm{~dB}$ is $14.1 \%$ (from $9.88 \mathrm{GHz}$ to $11.38 \mathrm{GHz}$ ), which is larger than the ARBW of the element.
TABle 2: Performance comparison with the antennas from references.

\begin{tabular}{lccc}
\hline Case & RLBW & ARBW & Gain (dBic) \\
\hline $\begin{array}{l}\text { Reference [2] array } \\
(16)\end{array}$ & $2.5 \%$ & - & 16.7 \\
$\begin{array}{l}\text { Reference [3] } \\
\text { element }\end{array}$ & $2.9 \%$ & $0.8 \%$ & - \\
$\begin{array}{l}\text { Reference [4] } \\
\text { element }\end{array}$ & $6.3 \%$ & - & 6.0 \\
$\begin{array}{l}\text { Reference [5] } \\
\text { element }\end{array}$ & $18.74 \%$ & $2.3 \%$ & 5.75 \\
$\begin{array}{l}\text { Reference [6] } \\
\text { element }\end{array}$ & $17.32 \%$ & $2.34 \%$ & 7.79 \\
$\begin{array}{l}\text { Reference [7] } \\
\text { element }\end{array}$ & $10.3 \%$ & $2.6 \%$ & 8.0 \\
$\begin{array}{l}\text { Current design } \\
\text { Element }\end{array}$ & $14.5 \%$ & $3.4 \%$ & 8.1 \\
\multicolumn{1}{c}{ Array (4) } & $19.2 \%$ & $14.1 \%$ & 13.48 \\
\hline
\end{tabular}

This result has validated the effectiveness of the sequential rotation method. The measured peak gain in the boresight direction is $13.48 \mathrm{dBic}$ at $10.3 \mathrm{GHz}$, while the simulated peak gain is $13.55 \mathrm{dBic}$. This discrepancy may be caused by an additional loss introduced by the transition between SMA and microstrip line. From $10.1 \mathrm{GHz}$ to $10.7 \mathrm{GHz}$, the antenna array has a stable gain of more than $12 \mathrm{dBic}$. The simulated Table 2 compares the performance of the antennas from the references and the antenna in this study. The antenna element obviously has a better ARBW. Moreover, impedance bandwidth and ARBW have been improved significantly through sequential rotation method.

Radiation efficiency has been measured by using the $\mathrm{D} / \mathrm{G}$ method [20]; the measured and the simulated radiation efficiency, by taking the finite conductivity of the copper and the loss tangent of the considered dielectric material during the simulation process, is depicted in Figure 11. The simulated radiation efficiency is found to be more than $85 \%$ from $10.1 \mathrm{GHz}$ to $10.7 \mathrm{GHz}$, while the measured one is more than $80 \%$ with the measured error and SMA connector influence. 

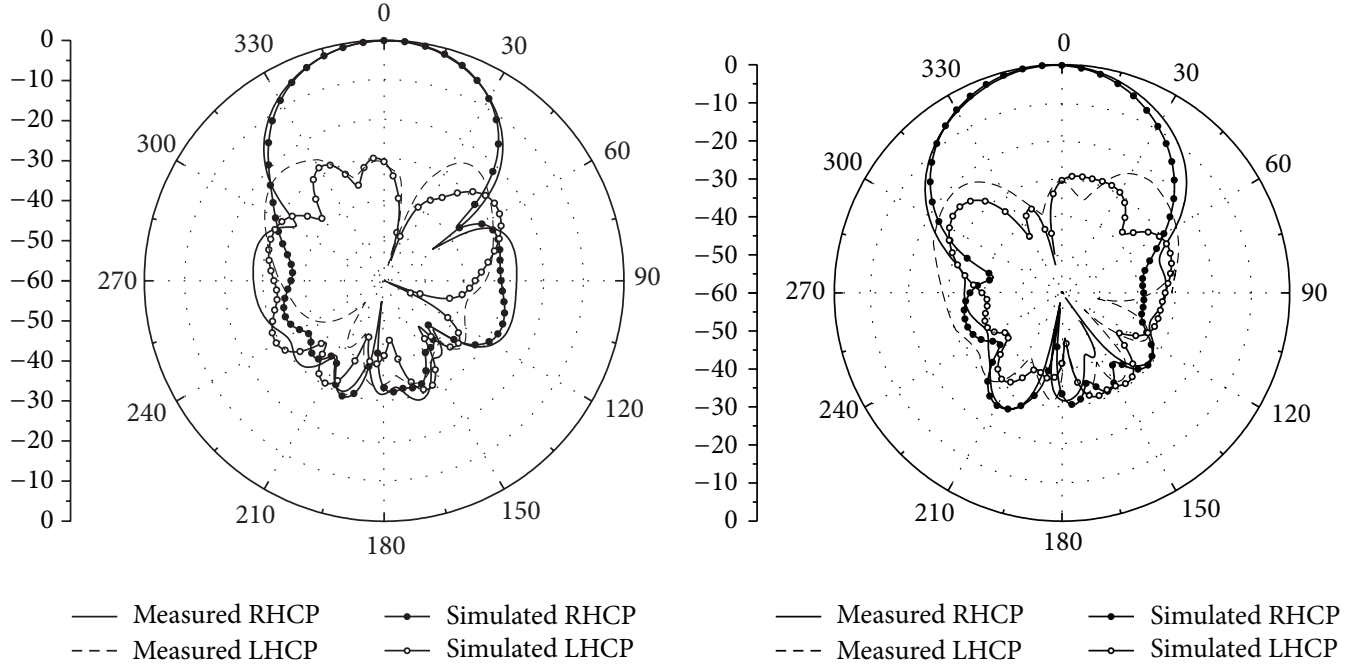

(b)

Figure 9: Measured and simulated radiation patterns at $10.3 \mathrm{GHz}$ (a) xoz plane and (b) yoz plane.

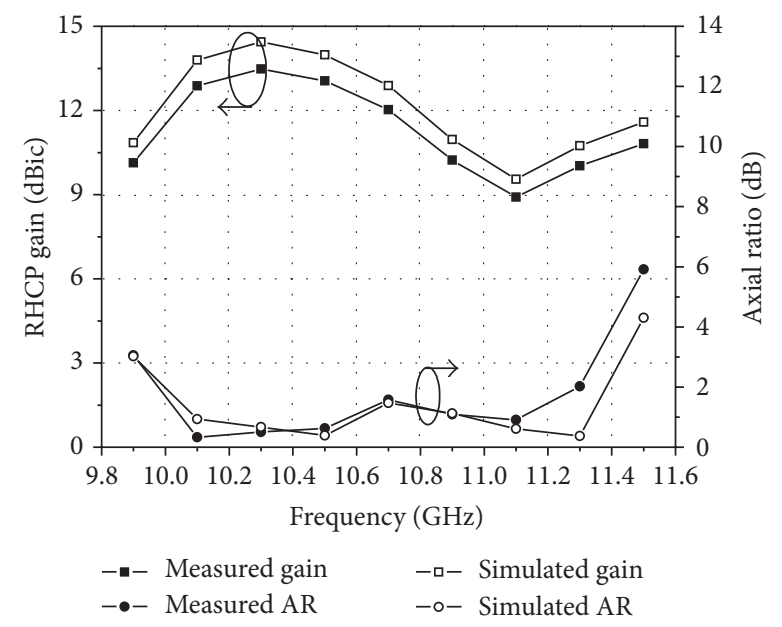

FIGURE 10: Measured and simulated gain, AR versus frequency.

\section{Conclusion}

In summary, a RHCP antenna array with high gain, high radiation efficiency, and large AR bandwidth is presented in this study. A large AR bandwidth is obtained by employing the sequential rotation feeding method. This method is simple and easy to fabricate. The SIW antenna array achieves $19.2 \%$ impedance bandwidth and $14.1 \%$ AR bandwidth. The realized peak gain is $13.48 \mathrm{dBic}$ at the boresight with a low cross-polarization at $10.3 \mathrm{GHz}$.

\section{Conflict of Interests}

The authors declare that there is no conflict of interests regarding the publication of this paper.

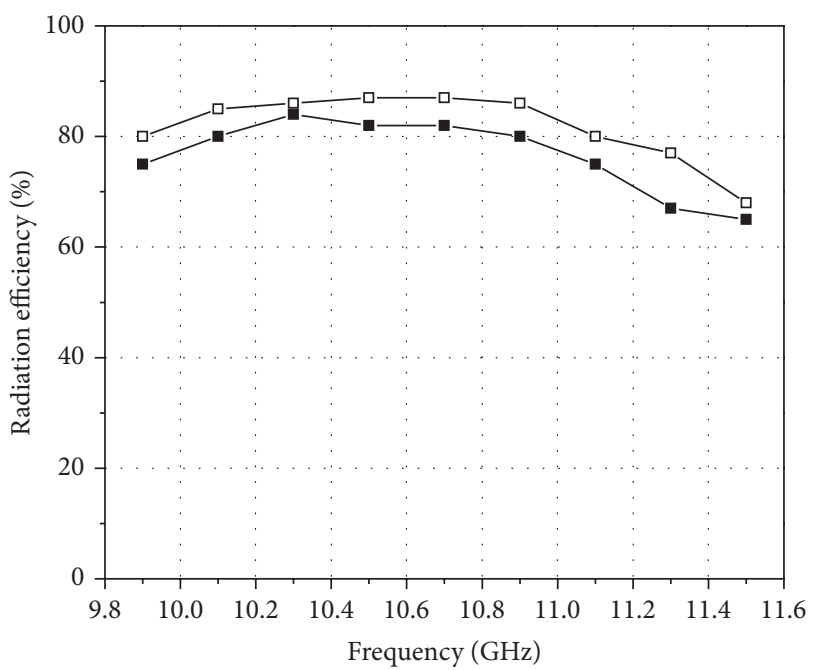

FIGURE 11: Measured and simulated radiation efficiency versus frequency.

\section{Acknowledgments}

This work was supported by the National Natural Science Foundation of China Project under Grant 61301068 and the Fundamental Research Funds for the Central Universities under Grants K50511020018 and K5051302075.

\section{References}

[1] $\mathrm{F} . \mathrm{Xu}$ and $\mathrm{K}$. Wu, "Guided-wave and leakage characteristics of substrate integrated waveguide," IEEE Transactions on Microwave Theory and Techniques, vol. 53, no. 1, pp. 66-73, 2005.

[2] P. Chen, W. Hong, Z. Kuai, and J. Xu, "A substrate integrated waveguide circular polarized slot radiator and its linear array," 
IEEE Antennas and Wireless Propagation Letters, vol. 8, pp. 120123, 2009.

[3] G. Q. Luo, Z. F. Hu, Y. Liang, L. Y. Yu, and L. L. Sun, "Development of low profile cavity backed crossed slot antennas for planar integration," IEEE Transactions on Antennas and Propagation, vol. 57, no. 10, pp. 2972-2979, 2009.

[4] G. Q. Luo, Z. F. Hu, W. J. Li, X. H. Zhang, L. L. Sun, and J. F. Zheng, "Bandwidth-enhanced low-profile cavity-backed slot antenna by using hybrid SIW cavity modes," IEEE Transactions on Antennas and Propagation, vol. 60, no. 4, pp. 1698-1704, 2012.

[5] D. Kim, J. W. Lee, C. S. Cho, and T. K. Lee, "X-band circular ring-slot antenna embedded in single-layered SIW for circular polarisation," Electronics Letters, vol. 45, no. 13, pp. 668-669, 2009.

[6] D. Y. Kim, J. W. Lee, T. K. Lee, and C. S. Cho, "Design of SIW cavity-backed circular-polarized antennas using two different feeding transitions," IEEE Transactions on Antennas and Propagation, vol. 59, no. 4, pp. 1398-1403, 2011.

[7] J. Lacik, "Circularly polarized SIW square ring-slot antenna for X-band applications," Microwave and Optical Technology Letters, vol. 54, no. 11, pp. 2590-2593, 2012.

[8] Y. Li, Z. N. Chen, X. Qing et al., "Axial ratio bandwidth enhancement of $60-\mathrm{GHz}$ substrate integrated waveguide-fed circularly polarized LTCC antenna array," IEEE Transactions on Antennas and Propagation, vol. 60, no. 10, pp. 4619-4626, 2012.

[9] J. L. Masa-Campos, P. Rodriguez-Fernandez, M. Sierra-Péerez, and J. L. Fernandez-Jambrina, "Monopulse circularly polarized siw slot array antenna in millimetre band," Journal of Electromagnetic Waves and Applications, vol. 25, no. 5-6, pp. 857-868, 2011.

[10] J. Z. Peng, S.-Q. Xiao, X.-J. Tang, and J. C. Lu, "A novel ka-band wideband slot antenna for system-on-package application," Journal of Electromagnetic Waves and Applications, vol. 22, no. 11-12, pp. 1705-1712, 2008.

[11] G. Q. Luo, X. H. Zhang, L. X. Dong, W. J. Li, and L. L. Sun, "A gain enhanced cavity backed slot antenna using high order cavity resonance," Journal of Electromagnetic Waves and Applications, vol. 25, no. 8-9, pp. 1273-1279, 2011.

[12] T. Teshirogi, M. Tanaka, and W. Chujo, "Wideband circularly polarized array antenna with sequential rotations and phase shifts of elements," in Proceeding of the International Symposium on Antennas Propagation (ISAP '85), pp. 117-120, Tokyo, Japan, August 1985.

[13] P. S. Hall, "Application of sequential feeding to wide bandwidth, circularly polarised microstrip patch arrays," IEE Proceedings $H$ : Microwaves, Antennas and Propagation, vol. 136, no. 5, pp. 390398, 1989.

[14] J. W. Wu and J. H. Lu, " $2 \times 2$ Circularly polarized patch antenna arrays with broadband operation," Microwave and Optical Technology Letters, vol. 39, no. 5, pp. 360-363, 2003.

[15] Y. Lu, D. G. Fang, and H. Wang, "A wideband circularly polarized $2 \times 2$ sequentially rotated patch antenna array," Microwave and Optical Technology Letters, vol. 49, no. 6, pp. 1405-1407, 2007.

[16] H. Evans and A. Sambell, "Wideband $2 \times 2$ sequentially rotated patch antenna array with a series feed," Microwave and Optical Technology Letters, vol. 40, no. 4, pp. 292-294, 2004.

[17] A. Chen, Y. Zhang, Z. Chen, and C. Yang, "Development of a Ka-band wideband circularly polarized 64-element microstrip antenna array with double application of the sequential rotation feeding technique," IEEE Antennas and Wireless Propagation Letters, vol. 10, pp. 1270-1273, 2011.
[18] E. A. Soliman, S. Brebels, E. Beyne, and G. A. E. Vandenbosch, "Sequential-rotation arrays of circularly polarized aperture antennas in the MCM-D technology," Microwave and Optical Technology Letters, vol. 44, no. 6, pp. 581-585, 2005.

[19] F. Fan, Z. Yan, P. xu et al., "Sequential rotation feeds microstrip array," Microwave \& RF, 2013.

[20] Q. Lai, G. Almpanis, C. Fumeaux, H. Benedickter, and R. Vahldieck, "Comparison of the radiation efficiency for the dielectric resonator antenna and the microstrip antenna at $\mathrm{Ka}$ band," IEEE Transactions on Antennas and Propagation, vol. 56, no. 11, pp. 3589-3592, 2008. 

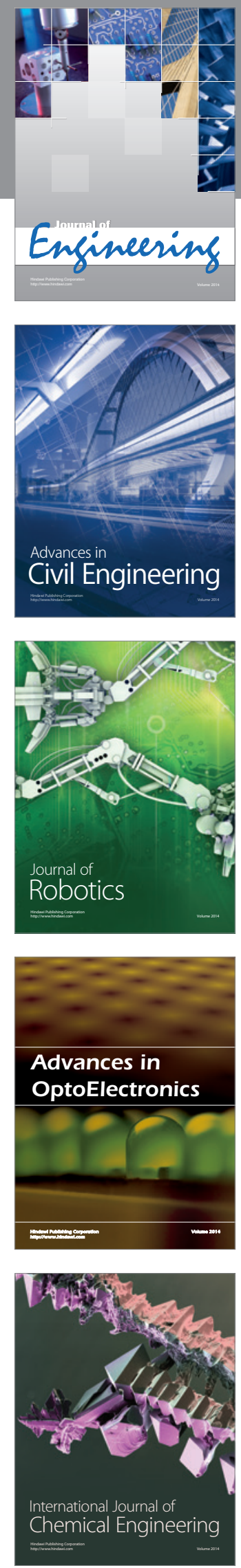

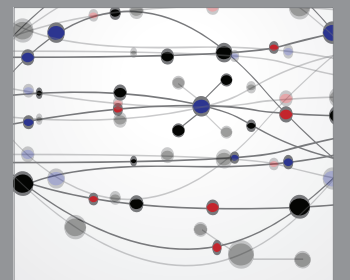

The Scientific World Journal
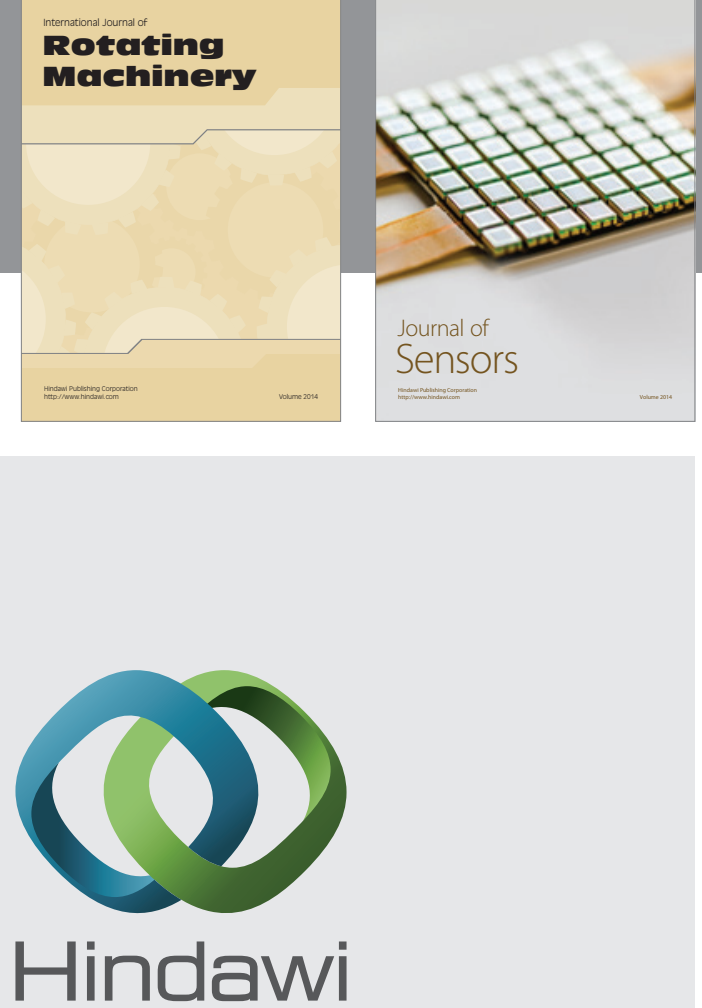

Submit your manuscripts at http://www.hindawi.com
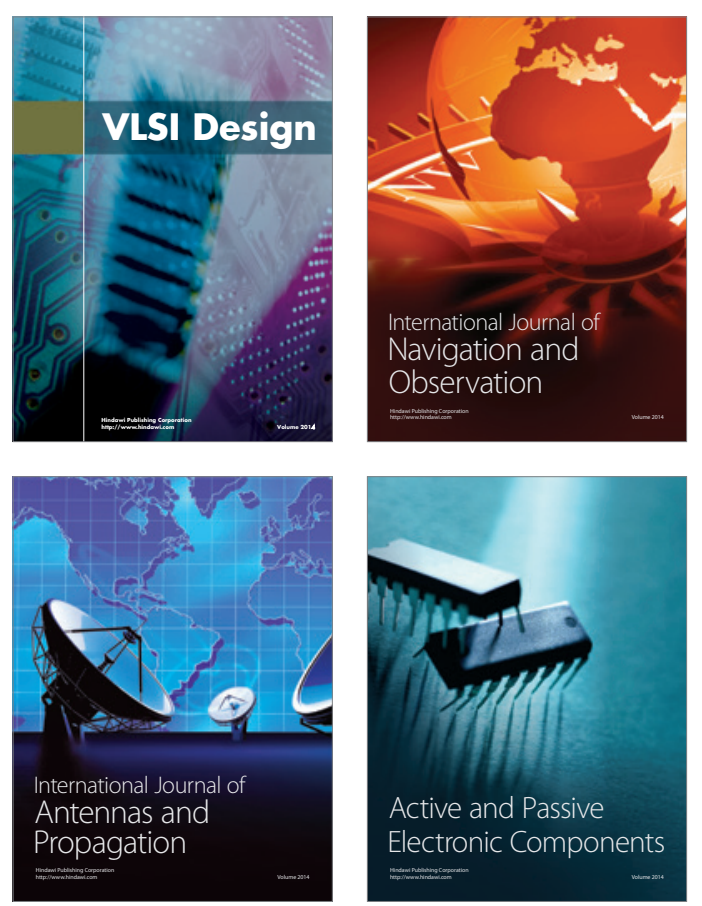
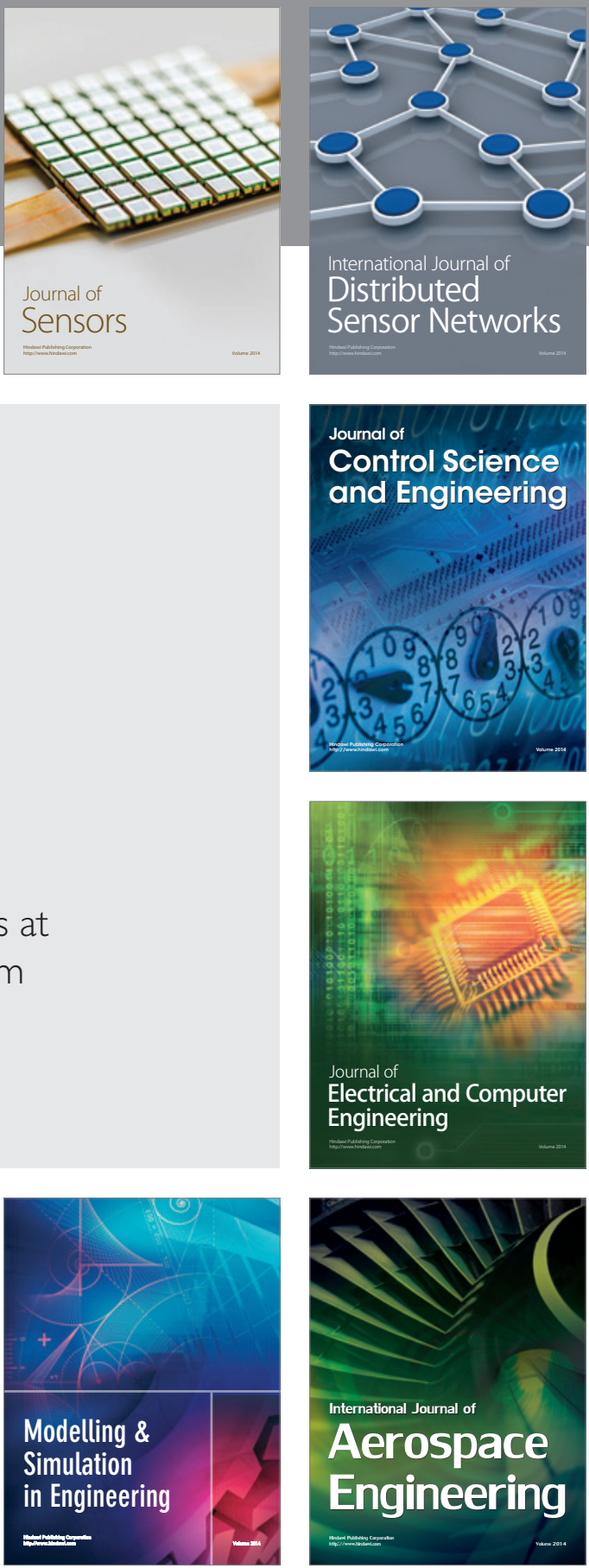

Journal of

Control Science

and Engineering
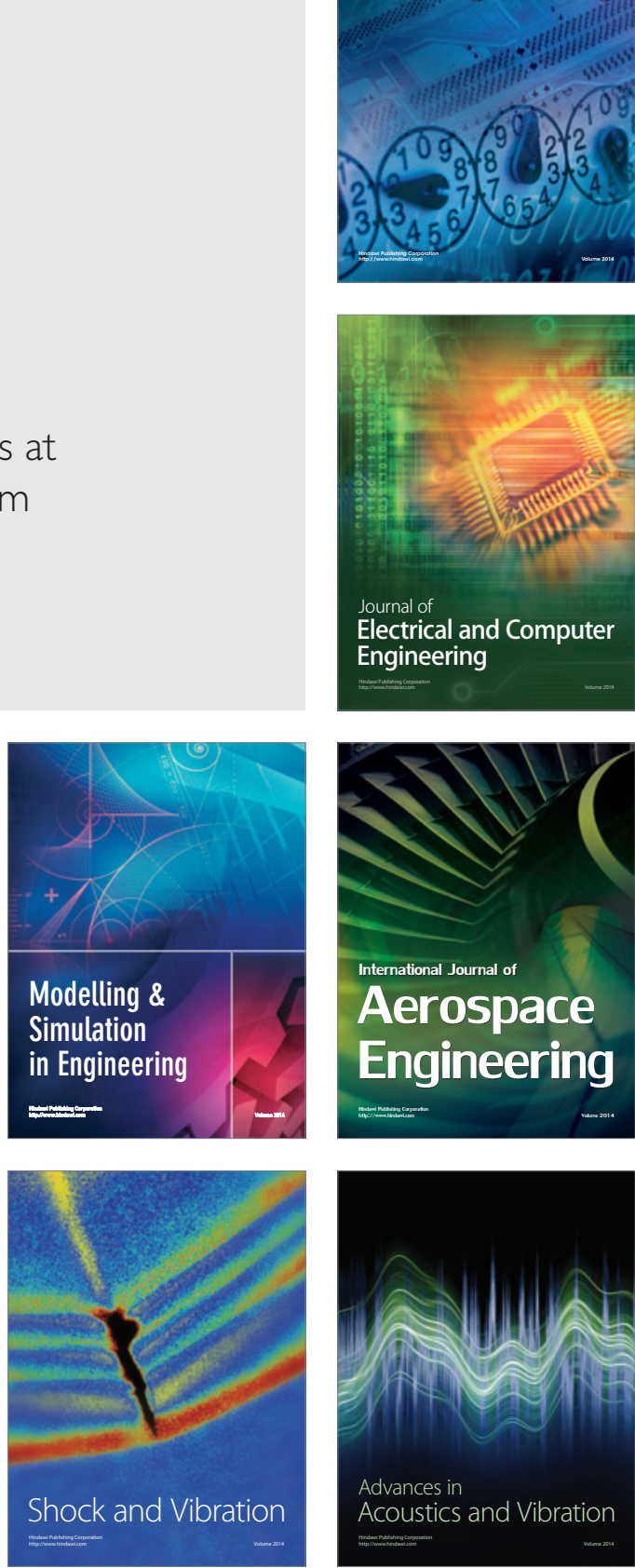